\title{
Spiralling into the nephrotic syndrome
}

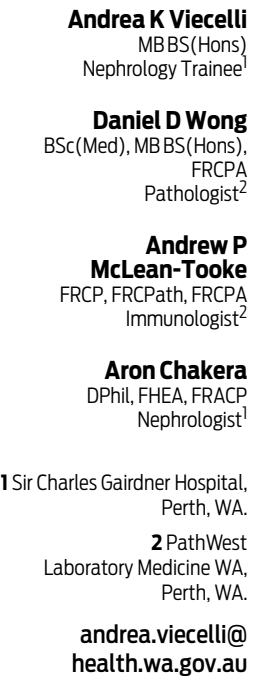

doi: 10.5694/mjal3.00016

\section{Clinical record}

A 35-year-old white woman presented to a peripheral hospital emergency department 18 days after giving birth to her second child at 33 weeks and 3 days of gestation. She had significant weight gain and increasing peripheral oedema that had started 12 days after the birth. She had no history of breathlessness, rash, ulcers, photosensitivity, arthralgia, recent travel, use of nonsteroidal anti-inflammatory drugs or use of recreational drugs. Both of her pregnancies had been complicated by hypertension, without proteinuria, and gestational diabetes, which had resolved spontaneously after each birth. Results of tests performed during the second trimester of her second pregnancy are shown in Box 1. Her past medical history included Raynaud phenomenon and adult attention deficit disorder, which was well controlled with dexamphetamine. She was a non-smoker and non-drinker and in a stable long-term relationship. She was referred by the peripheral hospital to the renal clinic of a large metropolitan hospital with suspected nephrotic syndrome.

The patient was reviewed in the renal clinic 21 days after the birth. On physical examination, her weight was $73 \mathrm{~kg}$ and both of her legs had marked pitting oedema. No rashes, lymphadenopathy or joint swelling were evident. Tests confirmed the nephrotic syndrome with a serum albumin level of $22 \mathrm{~g} / \mathrm{L}$ (reference interval [RI], 35-50 g/L) and heavy proteinuria (urinary protein-tocreatinine ratio, $1060 \mathrm{mg} / \mathrm{mmol}[\mathrm{Rl},<13 \mathrm{mg} / \mathrm{mmol}])$. There was no haematuria and her renal function was normal (serum creatinine level, $53 \mu \mathrm{mol} / \mathrm{L}$ [RI, 45-90 $\mathrm{mol} / \mathrm{L}]$; estimated glomerular filtration rate, $\left.>90 \mathrm{~mL} / \mathrm{min} / 1.73 \mathrm{~m}^{2}\left[\mathrm{RI},>60 \mathrm{~mL} / \mathrm{min} / 1.73 \mathrm{~m}^{2}\right]\right)$. She was started on oral frusemide $80 \mathrm{mg}$ twice daily and ramipril $1.25 \mathrm{mg}$ once daily. On review 3 days later, her physical examination findings were unchanged. Results of further tests are shown in Box 1. Results of serological tests for antibodies directed against M-type phospholipase $A_{2}$ receptors and serological tests for lupus were negative. As her condition had not improved, a renal biopsy was performed.

Light microscopy showed subtle glomerular changes in the biopsy specimen, including a minor increase in mesangial matrix,

yphilis is caused by the spirochaete bacterium Treponema pallidum. It is a re-emerging infection in the Western world. ${ }^{1}$ In Australia, there has been a marked increase in primary and secondary syphilis infections among non-Indigenous Australians over the past decade, particularly in men from metropolitan areas who are aged 20 years or older. During the same period, incidence rates for Indigenous people have fallen dramatically as a result of screening and preventive strategies. $^{2}$

Syphilis is known as "the great mimic" owing to the wide range of clinical presentations. Primary syphilis usually presents as a highly contagious ulcerated lesion (chancre) that appears 2-6 weeks after infection. Secondary syphilis manifests after haematogenous and lymphatic dissemination; symptoms include a non-itchy generalised rash, lymphadenopathy, fever and malaise and, less commonly, hepatitis, iritis, neurological symptoms and nephritis. Tertiary syphilis affecting the cardiovascular system or brain is a late manifestation and occurs after an incubation period of up to 15 years. Congenital syphilis subtle thickening of the capillary loops, inflammatory cells in the capillary loops and a suggestion of subepithelial deposits plus background vascular changes associated with hypertension (Box 2, A). Immunofluorescence microscopy showed moderate granular staining for IgG (Box 2, B) and Clq (Box 2, C) in capillary loops but minimal staining for $\mathrm{C} 3$. A definitive diagnosis could not be made on the basis of these results, so the sample was analysed by electron microscopy. This revealed subepithelial deposits (Box 2, D), which, coupled with the distribution of IgG on immunofluorescence microscopy, favoured a diagnosis of membranous glomerulonephritis.

The presence of Clq and inflammatory cells in capillary loops is uncommon in primary membranous glomerulonephritis, so a secondary cause was suspected and the patient underwent further testing. She had a significantly elevated rapid plasma reagin (RPR) titre of 1:256 and the diagnosis of active treponemal infection was confirmed by the presence of Treponema pallidum IgM and a positive $T$. pallidum particle agglutination test result (a reading of $4+$ ). She was given $1.8 \mathrm{~g}$ ( 2.4 million units) of benzathine penicillin by intramuscular injection and was screened for other sexually transmitted infections, for which results were all negative. Her baby was urgently assessed for congenital syphilis and found to be unaffected clinically. On further questioning, it was determined that the patient was likely to have acquired the disease 2 months before giving birth (during the second trimester) from her partner, who had noted a generalised rash and genital lesions at that time.

At 2-month follow-up, the patient's oedema had completely resolved, her weight had decreased to $63 \mathrm{~kg}$ and her proteinuria had lessened (urinary protein-to-creatinine ratio, $70 \mathrm{mg} / \mathrm{mmol}$ ). Frusemide and ramipril therapy were therefore withdrawn. She had a RPR titre of 1:32; this fourfold reduction is consistent with adequate treatment of the infection. At 7-month follow-up, her proteinuria had completely resolved (urinary protein-to-creatinine
ratio, $5 \mathrm{mg} / \mathrm{mmol}$ ) and her RPR titre was 1:8.

remains a significant cause of stillbirth, preterm labour and neonatal disease. ${ }^{3}$ When syphilis is detected early, treatment with benzathine penicillin can prevent longterm complications.

Renal manifestations of syphilis have been recognised since the 18th century. ${ }^{4}$ Proteinuria is the most common renal manifestation and occurs in up to $8 \%$ of patients with secondary syphilis. ${ }^{5}$ In addition to membranous nephropathy (MN) (eg, membranous glomerulonephritis), a variety of other renal conditions have been reported, including mesangioproliferative glomerulonephritis, rapidly progressive crescentic glomerulonephritis, and minimal change disease. ${ }^{5}$

$\mathrm{MN}$ is the most common cause of nephrotic syndrome in middle-aged white people and is characterised by formation of immune complexes on the subepithelial side of the glomerular capillaries. Although $\mathrm{MN}$ is usually primary (idiopathic), secondary causes should be considered if atypical histological features are found (as in our patient's case). ${ }^{6}$ Secondary causes of $\mathrm{MN}$ include drugs (non-steroidal anti-inflammatory drugs, auranofin 
1 Results of tests done during and after pregnancy

\begin{tabular}{|c|c|c|c|c|}
\hline \multirow[b]{2}{*}{ Blood and urine tests } & \multicolumn{2}{|r|}{ 2nd trimester } & \multicolumn{2}{|c|}{24 days after birth } \\
\hline & Result & Reference interval & Result & Reference interval \\
\hline Haemoglobin level (whole blood) & $115 \mathrm{~g} / \mathrm{L}$ & $115-160 \mathrm{~g} / \mathrm{L}$ & $112 \mathrm{~g} / \mathrm{L}$ & $115-160 \mathrm{~g} / \mathrm{L}$ \\
\hline Platelet count (whole blood) & $325 \times 10^{9} / \mathrm{L}$ & $150-400 \times 10^{9} / \mathrm{L}$ & $518 \times 10^{9} / \mathrm{L}$ & $150-400 \times 10^{9} / \mathrm{L}$ \\
\hline Serum albumin level & - & - & $26 \mathrm{~g} / \mathrm{Lg} / \mathrm{L}$ & $35-50 \mathrm{~g} / \mathrm{L}$ \\
\hline $\begin{array}{l}\text { 2-hour blood glucose level during oral glucose } \\
\text { tolerance test }\end{array}$ & $8.9 \mathrm{mmol} / \mathrm{L}$ & $\begin{array}{l}\geqslant 8.0 \mathrm{mmol} / \mathrm{L} \text { consistent with } \\
\text { gestational diabetes mellitus }\end{array}$ & - & - \\
\hline Urinary protein* & Trace & Negative & +++ & Negative \\
\hline Serum creatinine level & $68 \mu \mathrm{mol} / \mathrm{L}$ & 45-90 $\mu \mathrm{mol} / \mathrm{L}$ & $70 \mu \mathrm{mol} / \mathrm{L}$ & 45-90 $\mu \mathrm{mol} / \mathrm{L}$ \\
\hline Erythrocyte sedimentation rate & - & - & $127 \mathrm{~mm} / \mathrm{h}$ & $1-20 \mathrm{~mm} / \mathrm{h}$ \\
\hline Urinary protein-to-creatinine ratio & - & - & $577 \mathrm{mg} / \mathrm{mmol}$ & $<13 \mathrm{mg} / \mathrm{mmol}$ \\
\hline Hepatitis B surface antigen & Not detected & na & Not detected & na \\
\hline Hepatitis C antibodies & Not detected & na & Not detected & na \\
\hline HIV antibodies & Not detected & na & Not detected & na \\
\hline Varicella-zoster virus antibodies & Not detected & na & - & - \\
\hline Rubella IgG & $631 \mathrm{I} / \mathrm{mL}$ & $\geqslant 10.0 \mathrm{IU} / \mathrm{mL}$ presumed immune & - & - \\
\hline Syphilis antibodies $^{\dagger}$ & Not detected & na & - & - \\
\hline Thyroid-stimulating hormone & - & - & $2.5 \mathrm{mU} / \mathrm{L}$ & $0.4-4.0 \mathrm{mU} / \mathrm{L}$ \\
\hline Antinuclear antibodies & - & - & $4 \mathrm{IU} / \mathrm{mL}$ & $<7 I U / m L$ \\
\hline Anti-Sjögren syndrome antigen $A$ antibodies & - & - & Not detected & na \\
\hline Anti-double-stranded DNA antibodies & - & - & Not detected & na \\
\hline C3 & - & - & $1.35 \mathrm{~g} / \mathrm{L}$ & $0.78-1.50 \mathrm{~g} / \mathrm{L}$ \\
\hline $\mathrm{C} 4$ & - & - & $0.30 \mathrm{~g} / \mathrm{L}$ & $0.16-0.52 \mathrm{~g} / \mathrm{L}$ \\
\hline Antiphospholipase $A_{2}$ receptor antibodies & - & - & Not detected & na \\
\hline
\end{tabular}

\section{Results of histopathological analysis of renal biopsy specimen}
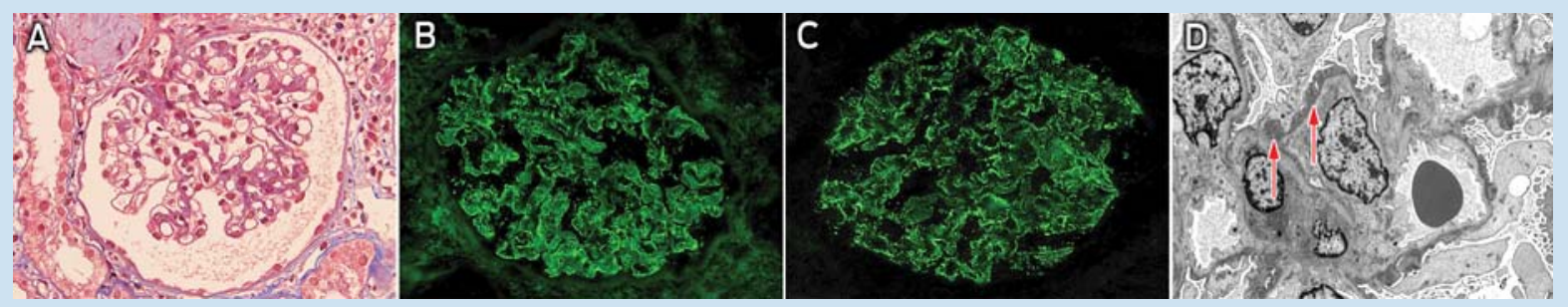

A: Light microscopy showed a minor increase in the glomerular mesangial matrix and subtle thickening of the capillary loops (Masson trichrome stain; original magnification, $\times 400$ ). B: Immunofluorescence microscopy showed moderate granular staining for lgG in capillary loops (original magnification, $\times 400$ ). C: Immunofluorescence microscopy showed moderate staining for Clq in capillary loops (original magnification, $\times 400$ ). D: Electron microscopy showed frequent and variously sized subepithelial electron-dense deposits (arrows) (original magnification, $\times 4000$ ).

[a gold-containing compound] and captopril), autoimmune disease (systemic lupus erythematosus), infections (hepatitis B, hepatitis C and syphilis) and malignancies (particularly lung, stomach, colon, breast, prostate and kidney). ${ }^{7}$ About $70 \%$ of primary $\mathrm{MN}$ is caused by autoantibodies directed against the $\mathrm{M}$-type antiphospholipase $\mathrm{A}_{2}$ receptor - a protein present on glomerular podocytes. Deposition of this antibody and the formation of subepithelial immune complexes results in complement-mediated podocyte injury and proteinuria. 6,8

The initial management of $\mathrm{MN}$ includes salt and fluid restriction, treatment with diuretics, and renin-angiotensin-aldosterone system inhibition to reduce oedema and minimise proteinuria. Prophylactic anticoagulation is recommended in patients with serum albumin levels of less than $20 \mathrm{~g} / \mathrm{L}$. Immunosuppression may be indicated to control disease in patients with primary $\mathrm{MN}$ who have progressive renal impairment and persisting nephrotic range proteinuria, but secondary $\mathrm{MN}$ often resolves after elimination of the underlying cause.

With the worldwide resurgence of sexually transmitted diseases, and the increase in treponemal infections occurring in Australia, clinicians should remain vigilant of the different clinical manifestations of syphilis.

Acknowledgements: We thank the staff at PathWest Laboratory Medicine WA for providing the histopathology images.
Competing interests: No relevant disclosures.

1 French P. Syphilis. BMJ 2007; 334: 143-147.

2 Ward JS, Guy RJ, Akre SP, et al. Epidemiology of syphilis in Australia: moving toward elimination of infectious syphilis from remote Aboriginal and Torres Strait Islander communities? Med J Aust 2011; 194: 525-529.

3 Humphrey MD, Bradford DL. Congenital syphilis: still a reality in 1996. Med J Aust 1996; 165: 382-385.

4 Thompson L. Syphilis of the kidney. JAMA 1920; 75: 17-20.

5 Hunte W, al-Ghraoui F, Cohen RJ. Secondary syphilis and the nephrotic syndrome. J Am Soc Nephrol 1993; 3: 1351-1355.

6 Beck LH Jr, Bonegio RG, Lambeau G, et al. M-type phospholipase A2 receptor as target antigen in idiopathic membranous nephropathy. N Engl J Med 2009; 361: 11-21.

7 Hofstra JM, Wetzels JF. Management of patients with membranous nephropathy. Nephrol Dial Transplant 2012; 27: 6-9.

8 Qin W, Beck LH Jr, Zeng C, et al. Anti-phospholipase A2 receptor antibody in membranous nephropathy. J Am Soc Nephrol 2011; 22: 1137-1143.

\section{Lessons from practice}

- Syphilis is a re-emerging sexually transmitted disease in non-Indigenous Australians and clinicians should be vigilant of the various clinical manifestations.

- Syphilis should be considered in the differential diagnosis of membranous nephropathy.

- Proteinuria is the commonest renal manifestation of syphilis.

- When syphilis is detected early, treatment with benzathine penicillin can prevent long-term complications. 